\title{
Article \\ The Connection between Czc and Cad Systems Involved in Cadmium Resistance in Pseudomonas putida
}

\author{
Huizhong Liu (D, Yu Zhang, Yingsi Wang, Xiaobao Xie * and Qingshan Shi * \\ Guangdong Provincial Key Laboratory of Microbial Culture Collection and Application, State Key Laboratory of \\ Applied Microbiology Southern China, Institute of Microbiology, Guangdong Academy of Sciences, \\ Guangzhou 510070, China; hzliucn@163.com (H.L.); zhangyu_1177@163.com (Y.Z.); wongvincy@163.com (Y.W.) \\ * Correspondence: xiexb@gdim.cn (X.X.);jigan@gdim.cn (Q.S.)
}

Citation: Liu, H.; Zhang, Y.; Wang, Y.; Xie, X.; Shi, Q. The Connection between Czc and Cad Systems Involved in Cadmium Resistance in Pseudomonas putida. Int. J. Mol. Sci. 2021, 22, 9697. https://doi.org/ $10.3390 /$ ijms 22189697

Academic Editor:

Amelia Casamassimi

Received: 16 August 2021

Accepted: 3 September 2021

Published: 8 September 2021

Publisher's Note: MDPI stays neutral with regard to jurisdictional claims in published maps and institutional affiliations.

Copyright: (c) 2021 by the authors. Licensee MDPI, Basel, Switzerland. This article is an open access article distributed under the terms and conditions of the Creative Commons Attribution (CC BY) license (https:// creativecommons.org/licenses/by/ $4.0 /)$.

\begin{abstract}
Heavy metal pollution is widespread and persistent, and causes serious harm to the environment. Pseudomonas putida, a representative environmental microorganism, has strong resistance to heavy metals due to its multiple efflux systems. Although the functions of many efflux systems have been well-studied, the relationship between them remains unclear. Here, the relationship between the Czc and Cad systems that are predominantly responsible for cadmium efflux in P. putida KT2440 is identified. The results demonstrated that $\mathrm{CzcR3}$, the response regulator of two-component system CzcRS3 in the Czc system, activates the expression of efflux pump genes $c z c C B A 1$ and $c z c C B A 2$ by directly binding to their promoters, thereby helping the strain resist cadmium stress. CzcR3 can also bind to its own promoter, but it has only a weak regulatory effect. The high-level expression of $c z c R S 3$ needs to be induced by $\mathrm{Cd}^{2+}$, and this relies on the regulation of CadR, a key regulator in the Cad system, which showed affinity to $c z c R S 3$ promoter. Our study indicates that the Cad system is involved in the regulation of the Czc system, and this relationship is important for maintaining the considerable resistance to cadmium in P. putida.
\end{abstract}

Keywords: P. putida KT2440; CzcRS two-component system; CadR regulator; gene regulation; cadmium resistance

\section{Introduction}

Anthropogenic and geological activities release heavy metals into the environment, making heavy metal pollution a significant threat to human and ecosystem health $[1,2]$. With the rapid development of industries such as mining [3], plating [4], nano-metallic materials [5], and electronics [6], this problem is increasing. Common hazardous heavy metal pollutants include $\mathrm{As}, \mathrm{Cd}, \mathrm{Co}, \mathrm{Cr}, \mathrm{Cu}, \mathrm{Hg}, \mathrm{Mn}, \mathrm{Ni}, \mathrm{Pb}$, etc. Some of these metal ions (e.g., $\mathrm{Co}^{2+}, \mathrm{Cu}^{2+}$, and $\mathrm{Mn}^{2+}$ ) are essential for biological processes at trace concentration [7]. To obtain these important metal ions, bacteria encode a variety of uptake transporters. These transporters are usually low-specific and driven by the chemiosmotic gradient across the cytoplasmic membrane [7]. For instance, the chemiosmotic transporter CorA mediates the influx of $\mathrm{Mg}^{2+}, \mathrm{Co}^{2+}$ and $\mathrm{Ni}^{2+}$ [8], and the $\mathrm{Mn}^{2+}$ and $\mathrm{Zn}^{2+}$ transporters allow $\mathrm{Cd}^{2+}$ to enter the cell $[9,10]$. This mode of transportation easily causes bacteria to uptake excessive metal ions and some toxic heavy metals in the environment contaminated by heavy metals. Excessive heavy metals in organisms can disturb metabolic functions through the denaturing of proteins, generating reactive oxygen species, and disrupting the intracellular ion balance [11-13].

It has been reported that the soil in some regions contains multiple heavy metals, such as $\mathrm{Cd}(0.1-3.6 \mathrm{mg} / \mathrm{kg}), \mathrm{Cr}(51-207 \mathrm{mg} / \mathrm{kg}), \mathrm{Cu}(14-109 \mathrm{mg} / \mathrm{kg})$, and Pb (9.6-100 mg/kg) [14,15]. Bacteria in the environment are often exposed to heavy metals, thus they have evolved resistance systems to protect themselves from these hazardous substances. The sequestration of heavy metal ions by extracellular polymeric substances and metallothionein confers bacteria a certain degree of heavy metal tolerance $[16,17]$. Some bacteria can also transform heavy 
metal ions into non-toxic forms, for instance, $\mathrm{Cd}^{2+}$ can be immobilized by biosynthesizing $\mathrm{CdS}$ quantum dots in Pseudomonas fragi and Cd-containing nanoparticle inclusions in Cupriavidus species $[18,19]$. Alternatively, expulsion through efflux systems is a more common and effective way to protect bacteria from heavy metals. The transportation of different heavy metals is generally driven by one or several specific efflux pumps; therefore, bacteria usually encode many different types of efflux pump systems in the genome and plasmid $[20,21]$. The diversity of heavy metal resistant genes in a bacterial strain, which is partly promoted by horizontal gene transfer, results in multiple heavy metal resistant phenotypes [22].

The cadmium efflux system, which mainly consists of the Czc system and Cad system, is a well-characterized mechanism of heavy metal resistance in bacteria [23]. The Czc system is composed of CzcCBA, CzcRS, and CzcD. CzcCBA, a transporter across the inner and outer membranes, is assembled from the outer membrane protein $\mathrm{CzcC}$, the membrane fusion protein $\mathrm{CzcB}$, and the inner membrane protein $\mathrm{CzcA}$ [24]. It functions as a cation-proton antiporter to transport excess $\mathrm{Cd}^{2+}, \mathrm{Zn}^{2+}$, and $\mathrm{Co}^{2+}$ in the cytoplasm and periplasm to outside the cell [25]. The expression of $c z c C B A$ operon is regulated by the two-component system CzcRS. The regulatory effect of CzcRS can be activated by $\mathrm{Cd}^{2+}, \mathrm{Zn}^{2+}$, and $\mathrm{Co}^{2+}[26]$. Structural and functional analysis showed that when the periplasmic sensor domain of the histidine kinase $\mathrm{CzcS}$ binds to $\mathrm{Zn}^{2+}$, the intracellular kinase domain of $\mathrm{CzcS}$ will autophosphorylate and then transmits the phosphate group to the intracellular response regulator CzcR [27]. Subsequently, the phosphorylated CzcR promotes the transcription of $c z c C B A$. CzcD is a cation diffusion facilitator (CDF) protein family transporter located in the cytoplasmic membrane. It can also reduce $\mathrm{Cd}^{2+}, \mathrm{Zn}^{2+}$, and $\mathrm{Co}^{2+}$ accumulation in the cytoplasm, but only provides a small degree of resistance to metal ions compared to CzcCBA [28,29]. The Cad system contains the P-type ATPase superfamily efflux pump CadA, the ArsR/SmtB family regulator CadC, and the MerR family transcriptional regulator CadR. CadR has a high affinity to $\mathrm{Cd}^{2+}$ and a relatively weak affinity to $\mathrm{Zn}^{2+}$ and $\mathrm{Pb}^{2+}[30]$. When the CadR dimer binds $\mathrm{Cd}^{2+}$, it can distort the targeted promoter, leading to transcription activation of the targeted genes [30]. CadA, which is expressed under the control of CadR, is an effective transporter for expelling $\mathrm{Cd}^{2+}$ in the cytoplasm to the periplasm by utilizing the energy from ATP decomposition [30,31]. CadC, which is encoded immediately downstream of cadA in Staphylococcus aureus, acts as a transcriptional repressor of $c a d A-c a d C$ operon [32]. In some bacteria, such as Ralstonia metallidurans and Pseudomonas putida, the Czc and Cad systems are both important to confer full resistance to several heavy metals: the elimination of either system would significantly reduce resistance to $\mathrm{Cd}^{2+}$ and $\mathrm{Zn}^{2+}[33,34]$.

P. putida is a class of beneficial bacteria that exists widely in terrestrial and aquatic environments [35]. It can efficiently degrade various organic pollutants and promote plant growth [36,37]. Due to the development of genetic tools designed for genome editing, and the deep understanding of metabolic pathways, P. putida strains have been engineered as bacterial platforms for the biosynthesis of industrially relevant compounds such as cis,cismuconic acid $[38,39]$. Some P. putida strains isolated from areas contaminated with heavy metal contaminants, such as P. putida CD2 and P. putida X4, show strong resistance to some hazardous heavy metals, especially cadmium [40,41]. These resistances are inseparable from the contribution of the Czc and Cad systems encoded in their genomes. However, so far, few studies have focused on the connection that evolved under heavy metal stress between these two types of efflux systems. In this study, the representative environmental model strain P. putida KT2440 [42] was used to explore the relationship between the Czc and Cad systems. The results provide insights into the regulatory connection between CadR, CzcRS3, and CzcCBA at a molecular level, and their roles in cadmium resistance of P. putida. 


\section{Results and Discussion}

\subsection{Involvement of Two-Component System CzcRS3 in Heavy Metal Resistance}

Among the three $c z c R$ genes predicted in the P. putida KT2440 genome (Pseudomonas Genome Database version 20.2, https: / /www.pseudomonas.com, accessed on 3 September 2021), czcR1 (PP_0029) and czcR3 (PP_1438) are immediately followed by a cognate histidine kinase encoding gene (czcS), while czcR2 (PP_0047) is orphaned [43]. In P. putida X4, the homologous operon of $c z c R S 1$ could maintain a considerable expression level without metal ion inducers and is even repressed by $\mathrm{Zn}^{2+}$ and $\mathrm{Cd}^{2+}$, whereas the homologous operon of $c z c R S 3$ needs to be induced by $\mathrm{Cd}^{2+}$ for expression [41]. This implies that $c z c R S 3$ of P. putida KT2440 may be more related to cadmium resistance. Therefore, the role of this two-component system in heavy metal resistance, and the regulation of its expression, was the focus of this study. Firstly, the $c z c R S 3$ was inactivated by homologous recombination, and the modifications in heavy metal resistance were tested. The MIC of $\mathrm{Cd}^{2+}$ in LB medium was reduced by four-fold in the $c z c R S 3$ deletion mutant $(\Delta c z c R S 3)$, while no change was observed in the MICs of other heavy metals $\left(\mathrm{Co}^{2+}, \mathrm{Cr}^{3+}, \mathrm{Cu}^{2+}, \mathrm{Mn}^{2+}\right.$, $\mathrm{Ni}^{2+}, \mathrm{Pb}^{2+}$, and $\left.\mathrm{Zn}^{2+}\right)$, compared to that in the wild-type (Table 1). When the cloned $c z c R S 3$ was expressed under the control of the inducible tac promoter in $\triangle c z c R S 3$ ( $\triangle c z c R S 3(c z c R S 3 \mathrm{oe})$ ), cadmium resistance was significantly increased, to a level that exceeded the wild-type level (Figure 1). These results indicate that CzcRS3 plays an important role in cadmium resistance of P. putida KT2440.

Table 1. Minimum inhibitory concentration (MIC) of heavy metals for wild-type P. putida KT2440 and $\triangle c z c R S 3$ in LB medium.

\begin{tabular}{ccccccccc}
\hline Metal Ion (mM) & $\mathbf{C d}^{2+}$ & $\mathbf{C o}^{2+}$ & $\mathbf{C r}^{3+}$ & $\mathbf{C u}^{2+}$ & $\mathbf{M n}^{2+}$ & $\mathbf{N i}^{2+}$ & $\mathbf{P b}^{2+}$ & $\mathbf{Z n}^{2+}$ \\
\hline wild-type & 1 & 1 & 4 & 8 & 16 & 8 & 8 & 8 \\
$\Delta c z c R S 3$ & 0.25 & 1 & 4 & 8 & 16 & 8 & 8 & 8 \\
\hline
\end{tabular}
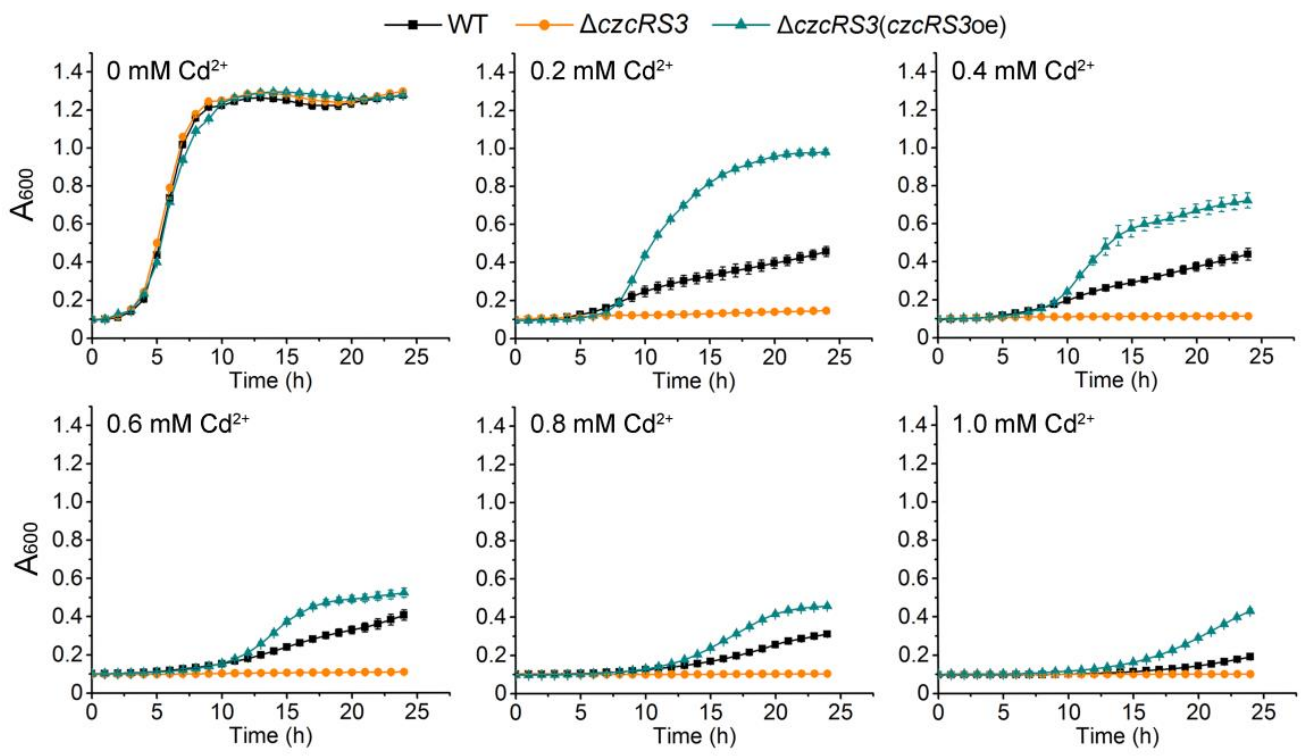

Figure 1. The role of $c z c R S 3$ in Pseudomonas putida cadmium resistance. The wild-type P. putida KT2440 (WT, black), deletion $\Delta c z c R S 3$ (orange), and overexpressed $\Delta c z c R S 3$ (czcRS3oe) (blue, harboring pB403$c z c R S 3)$ cells were incubated in LB medium supplemented with $\mathrm{CdCl}_{2}$ at concentrations ranging from 0 to $1 \mathrm{mM}$. The absorbance at $600 \mathrm{~nm}\left(\mathrm{~A}_{600}\right)$ was measured to evaluate the bacterial growth under cadmium stress. The data represent the mean \pm standard deviation of three replicates.

\subsection{CzcRS3 Controls the Expression of Two CzcCBA Efflux Pumps}

The genome of KT2440 encodes several efflux pumps ( $c z c D$, cadA1, cadA2, cadA3, $c z c C B A 1, c z c C B A 2$, and $c z c C-c u s B A)$ that have a clear or putative relationship with cadmium 
resistance $[34,43,44]$. To elucidate the decreased cadmium resistance of $\Delta c z c R S 3$, the expression of these genes in $\triangle c z c R S 3$ was detected by promoter-fused lacZ ( $\beta$-galactosidase encoding gene) reporter plasmids. As shown in Figure 2A, the expression of $c a d A 1$ and $c z c C$-cusBA was not detected in either wild-type or $\triangle c z c R S 3$, regardless of exposure to $\mathrm{Cd}^{2+}$. Their expression might need to be induced by other factors. This was supported by the fact that cadA1 maintained a very low or undetectable expression level without a divalent metal inducer, while $\mathrm{Zn}^{2+}$, but not $\mathrm{Cd}^{2+}$, was able to induce its expression [34]. In contrast, $c z c D$, cadA2, and $c a d A 3$ maintained significant expression levels in both the wild-type and $\triangle c z c R S 3$, with or without $\mathrm{Cd}^{2+}$ (Figure 2A). There was no visible difference in the expression of these five genes between the wild-type and $\Delta c z c R S 3$, suggesting that CzcRS3 did not regulate the expression of these efflux pumps.

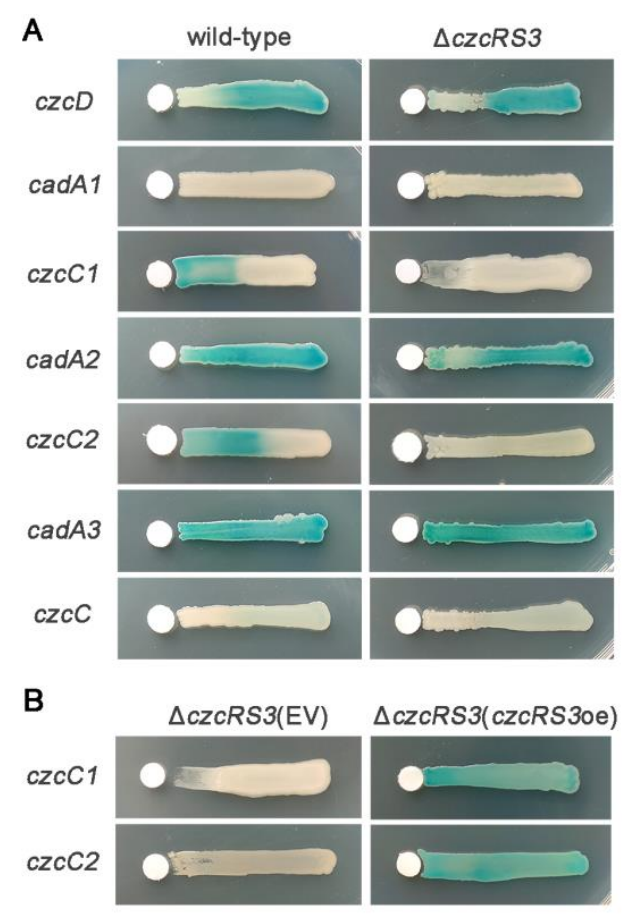

Figure 2. Role of CzcRS3 in the expression of efflux pump encoding genes. (A) The lacZ reporter plasmids carrying the promoter of indicated genes (the first gene of the operons) were introduced into wild-type KT2440 and deletion $\triangle c z c R S 3$. (B) The empty vector pBBR1-403 (EV) and pB403-czcRS3 ( $c z c R S 30 e$ ) were introduced into the $\triangle c z c R S 3$ strains harboring the reporter plasmid for either $c z c C 1$ or $c z c C 2$. The fresh bacterial cultures were streaked on the LB agar containing $40 \mu \mathrm{g} / \mathrm{mL} \mathrm{X-gal}$ (5-bromo-4-chloro-3-indolyl $\beta$-D-galactopyranoside). The filter paper pieces on the left side were supplemented with $4 \mu \mathrm{L}$ of $0.1 \mathrm{M} \mathrm{CdCl}_{2}$. The blue substance, which is the hydrolyzed product of $\mathrm{X}$-gal by LacZ, indicates activation of the tested promoters. The photos were taken after $4 \mathrm{~d}$ of incubation.

The activation of $c z c C B A 1$ and $c z c C B A 2$ promoters in the wild-type could not be detected under the cadmium-free condition, but increased significantly upon exposure to $\mathrm{Cd}^{2+}$ (Figure 2A). However, when $c z c R S 3$ was knocked out, these two operons were no longer induced by $\mathrm{Cd}^{2+}$, indicating that expression of $c z c C B A 1$ and $c z c C B A 2$ relied on CzcRS3 and $\mathrm{Cd}^{2+}$ (Figure 2A). To further verify this, $c z c R S 3$ was supplemented to the mutant by a plasmid carrying the cloned $c z c R S 3$ driven by the inducible tac promoter, which could avoid the interference from the regulators involved in $c z c R S 3$ expression. As expected, the expression of $c z c C B A 1$ and $c z c C B A 2$ in $\triangle c z c R S 3$ was triggered by the expression of $c z c R S 3$ (Figure 2B). Interestingly, the cells of $\triangle c z c R S 3$ with overexpressed $c z c R S 3$ ( $\triangle c z c R S 3(c z c R S 3$ oe)) on the cadmium-free side could also activate the expression of these two efflux pumps (Figure 2B). These results imply that CzcRS3 is the key regulator 
for $c z c C B A 1$ and $c z c C B A 2$ expression, and $\mathrm{Cd}^{2+}$ plays a role in other processes rather than the activation of their expression by CzcRS3. A previous study has investigated the roles of these two CzcCBA efflux pumps in heavy metal resistance, and showed that deletion of $c z c A 1$ significantly reduced the resistance of the strain to $\mathrm{Cd}^{2+}$ and $\mathrm{Zn}^{2+}$ in minimal medium, whereas $c z c A 2$ deletion did not affect the sensitivity to heavy metals [34]. This suggests that the decrease in cadmium resistance of $\triangle c z c R S 3$ is probably due to the blocking of $c z c C B A 1$ expression.

\subsection{CzcR3 Directly Binds to the Promoters of $c z c C B A 1$ and $c z c C B A 2$}

Response regulators function by binding to the targeted promoters and activating or inhibiting transcription events, after being phosphorylated by the cognate histidine kinase [45]. Although CzcR has a significant regulatory role in gene expression, its binding site on promoter has rarely been identified. Thus, the binding of CzcR3 to the promoter of $c z c C B A 1$ and $c z c C B A 2$ was explored. Electrophoresis analysis showed that purified CzcR3 was able to form a homodimer in vitro (Figure S1), which was expected since its cognate histidine kinase $\mathrm{CzcS}$ could also occur dimerization [27]. Since the response regulators displayed a much higher DNA-binding affinity after phosphorylation [26,46], carbamyl phosphate was used as a phosphate group donor, which could be used for in vitro phosphorylation of response regulators, such as ArcA [47] and NtrC [48]. The EMSA results showed that, in the presence of carbamyl phosphate, CzcR3 had an affinity for the promoters of $c z c C 1$ and $c z c C 2$ (Figure $3 \mathrm{~A}, \mathrm{C}$ ). To further identify the binding site of CzcR3 on the promoters, a DNase I footprinting assay was performed. The results showed that, relative to the translation start site, CzcR3 bound to the regions from -120 to $-144 \mathrm{bp}$ for $c z c \mathrm{C} 1$ and -45 to $-69 \mathrm{bp}$ for $c z c C 2$ (Figure 3B,D). There was a high degree of similarity between these two sequences, and they displayed a common inverted repeat sequence (aTTAC-N6-GTAAT) internally, in which the 6 bp spacer was likely to be rich in A/T (Figure 3E). This feature was also found in the DNA-binding sequence of CzcR in Pseudomonas stutzeri [49].

A

$\begin{array}{llllllll}\operatorname{CzcR} 3(\mu \mathrm{M}) & 0 & 0.5 & 1 & 0.5 & 0.5 & 1 & 1\end{array}$

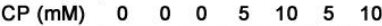

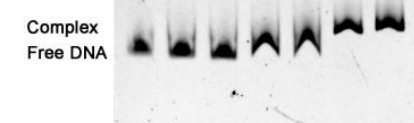

C \begin{tabular}{llllllll} 
CzcR3 $(\mu M)$ & 0 & 0.5 & 1 & 0.5 & 0.5 & 1 & 1 \\
\hline
\end{tabular}

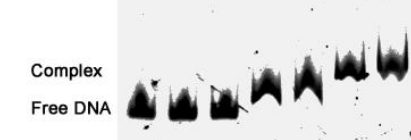

E $\begin{array}{ll} & \text { CzcR3-binding region } \\ \text { czcC1 } & - \text { CTTTCTTACGAAATTGTAATTTTCT } \\ & -*-*--* * * *-* * * * * * * * * *-* *--\end{array}$
B

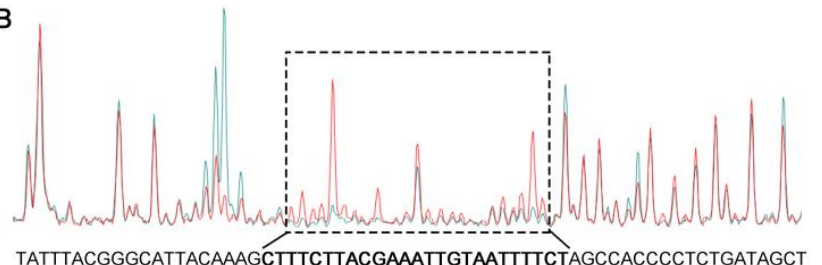

TATTTACGGGCATTACAAAGCTTTCTTACGAAATTGTAATTTTCTAGCCACCCCTCTGATAGCT ACCGCTCATTAGAGTGCCATCACCTAATCAAGTGGGGCTTGGCAGCTGTTTCGGCGTTCTCGC CAAGCTTTATCGAAGTTTGTGCACGAGGACCATCAAAGTGCCCCGGTATAACCGCAATGTCTT

D

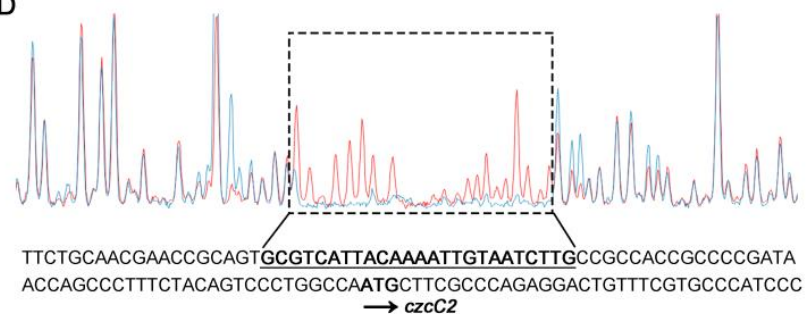

Figure 3. The binding of $\mathrm{CzcR} 3$ to the promoters of two $c z c C B A$ operons. $(\mathbf{A}, \mathbf{C})$ The FAM-tagged promoter probes of $c z c C 1(\mathbf{A})$ and $c z c C 2(\mathbf{C})$ were subjected to EMSA with the purified CzcR3 and carbamyl phosphate (CP). The hysteretic bands indicate the complex of CzcR3 and the probes. (B,D) The binding sites of $\mathrm{CzcR} 3$ on promoters of $c z c C 1$ (B) and $c z c C 2$ (D) were identified by Dnase I footprinting assay, in which the probe was incubated with CzcR3 (blue peak) or BSA (red peak, as control). The region in the dashed box, which displays the blue peak weaker than the red control, represents the binding region of $\mathrm{CzcR} 3$ on the promoter. The arrows indicate the translation start sites of $c z c C 1$ (B) and $c z c C 2$ (D). (E) The binding sequences of $\mathrm{CzcR3}$ on $c z c C 1$ and $c z c C 2$ promoters show a high degree of similarity. 


\subsection{Identification of the Transcription Pattern of $c z c R S 3$}

To determine the role of CzcRS3 in cadmium resistance, the regulation of the czcRS3 operon was studied. The expression level of $c z c R S 3$ in the wild-type strain was evaluated by the reporter plasmid for $c z c R 3$. When heavy metals were absent, the $c z c R S 3$ promoter exhibited low transcription activity (Figure $4 \mathrm{~A}$ ). Several heavy metals, including $\mathrm{Cd}^{2+}$, $\mathrm{Co}^{2+}, \mathrm{Cr}^{3+}, \mathrm{Cu}^{2+}, \mathrm{Mn}^{2+}, \mathrm{Ni}^{2+}, \mathrm{Pb}^{2+}$, and $\mathrm{Zn}^{2+}$, were used as inducers, at a concentration of $1 / 5$ MIC. Among these inducers, only $\mathrm{Cd}^{2+}$ could strongly induce $c z c R S 3$ expression, reflecting the important relationship between CzcRS3 and cadmium resistance. $\mathrm{Pb}^{2+}$ and $\mathrm{Zn}^{2+}$ also displayed an inducing effect on $c z c R S 3$ expression, but much weaker than $\mathrm{Cd}^{2+}$ (Figure 4A).

A

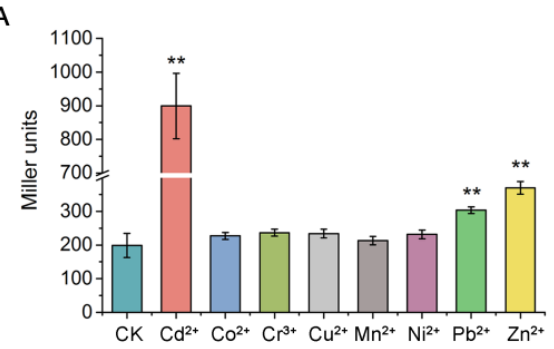

D

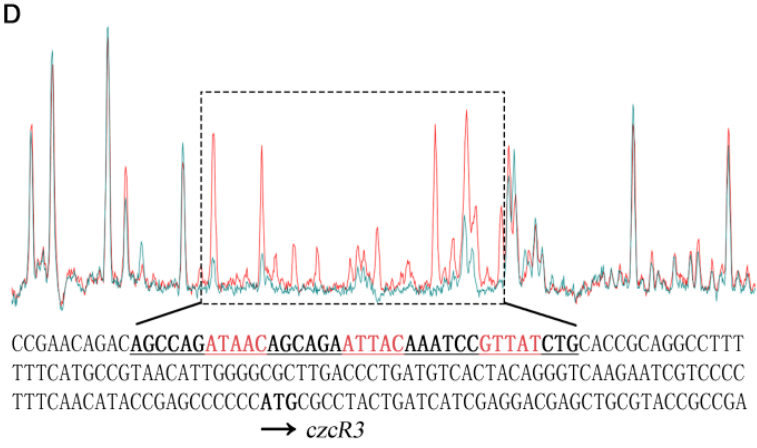

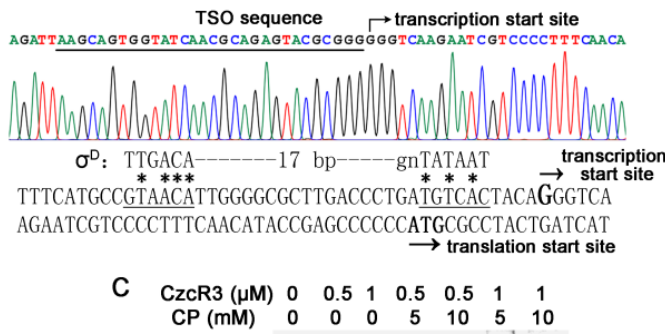

Complex

Free DNA

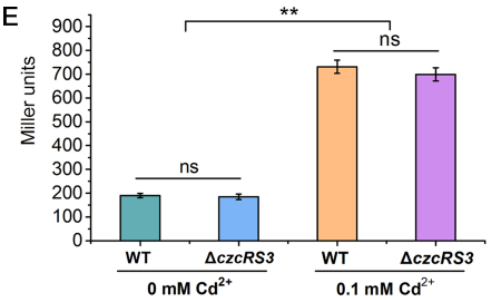

Figure 4. The regulation of $c z c R S 3$ expression. (A) Induction of heavy metals on $c z c R S 3$ expression. The expression level of $c z c R S 3$ in wild-type KT2440 was detected by reporter plasmid pBRTZ-czcR3 after treatment with heavy metals at a concentration of $1 / 5 \mathrm{MIC}$ for $4 \mathrm{~h}$. (B) Identification of the transcription start site of $c z c R S 3$ operon by $5^{\prime}$-RACE assay. The underlined -10 and -35 elements show similarity to the recognition sequence of $\sigma^{\mathrm{D}}$ (* indicates the matched DNA bases). (C) The affinity of CzcR3 for $c z c R S 3$ promoter in presence of carbamyl phosphate (CP). (D) Identification of the CzcR3-binding site on $c z c R S 3$ promoter. The promoter probes were incubated with CzcR3 (blue peak) or BSA (red peak, as control) in DNase I footprinting assay. The region in the dashed box represents the binding region of CzcR3 on the promoter. (E) The regulatory role of CzcRS3 in self-expression. The data represent the mean \pm standard deviation of three replicates. The significant difference was determined by Student's $t$-test (** $p<0.01$; ns, non-significant, $p>0.05$ ).

Subsequently, the transcription start site of $c z c R S 3$ was identified by a $5^{\prime}$-RACE assay, which showed that it was located $39 \mathrm{bp}$ upstream of the translation start site of $c z c R 3$ (Figure 4B). The -10 and -35 elements of this transcription start site displayed similarity to the recognition sequence of sigma factor $\sigma^{\mathrm{D}}$ [50]. However, there were several mismatched nucleotides in the critical -10 element, suggesting that efficient transcription of $c z c R S 3$ might require the assistance of a positive regulator [51].

Analysis of the $c z c R S 3$ promoter indicated a potential CzcR3 binding site in the -116 to $-101 \mathrm{bp}$ region, relative to the first codon of $c z c R 3$, which showed a high similarity to the CzcR3-binding sites on the $c z c C 1$ and $c z c C 2$ promoters. EMSA verified the binding ability of CzcR3 to its own promoter (Figure 4C), while DNase I footprinting assay showed that CzcR3 protected the region between -98 and $-133 \mathrm{bp}$, relative to the first codon of $c z c R 3$ 
(Figure 4D). It should be noticed that this $36 \mathrm{bp}$ protected region was much longer than the CzcR3-protected region on $c z c C 1$ and $c z c C 2$ promoters, which were both approximately 25 bp (Figure 3B,D). Interestingly, this long protected region contained three putative CzcR3 recognition motifs (ATAAC, ATTAC, and GTTAT). Whether the binding complex contained two or three $\mathrm{CzcR} 3$ monomers could not be determined, since the structure of $\mathrm{CzcR} 3$ or its interaction with DNA has not yet been elucidated. To test the regulatory role of CzcRS3 on its encoding operon, the reporter plasmid pBRTZ-czcR3 was introduced into $\triangle c z c R S 3$. Surprisingly, the activity of $c z c R 3$ promoter in $\triangle c z c R S 3$ was not significantly different from that in the wild-type (Figure 4E). Under induction by $\mathrm{Cd}^{2+}$, both the wild-type and $\triangle c z c R S 3$ could effectively activate the $c z c R 3$ promoter (Figure $4 \mathrm{E}$ ), suggesting that the unconventional binding of $\mathrm{CzcR} 3$ to its promoter had no obvious regulatory effect. This also implies that there are other regulators involved in $c z c R S 3$ expression.

\section{5. $\mathrm{Cd}^{2+}$ Induces czcRS3 Expression through CadR}

CadR is a well-characterized transcriptional regulator that responds to $\mathrm{Cd}^{2+}, \mathrm{Zn}^{2+}$, and $\mathrm{Pb}^{2+}$ in P. putida KT2440 [30,52]. Along with the fact that $\mathrm{Cd}^{2+}, \mathrm{Zn}^{2+}$, and $\mathrm{Pb}^{2+}$ could induce $c z c R S 3$ expression (Figure 4A), it is possible that CadR participates in $c z c R S 3$ regulation. To confirm this hypothesis, the $c a d R$ deletion mutant $(\Delta c a d R)$ was constructed, and the expression of $c z c R S 3$ was determined in this mutant. As expected, the promoter of $c z c R S 3$, regardless of the presence of $\mathrm{Cd}^{2+}$, could not be activated in $\triangle c a d R$ (Figure 5A). When $\triangle c a d R$ was complemented with $c a d R(\Delta c a d R(c a d R o e))$, the activity of $c z c R S 3$ promoter was restored to the wild-type level, and increased significantly upon exposure of $0.1 \mathrm{mM} \mathrm{Cd}^{2+}$ (Figure 5A). This indicates that CadR is the key regulator in response to $\mathrm{Cd}^{2+}$ to activate the expression of $c z c R S 3$.
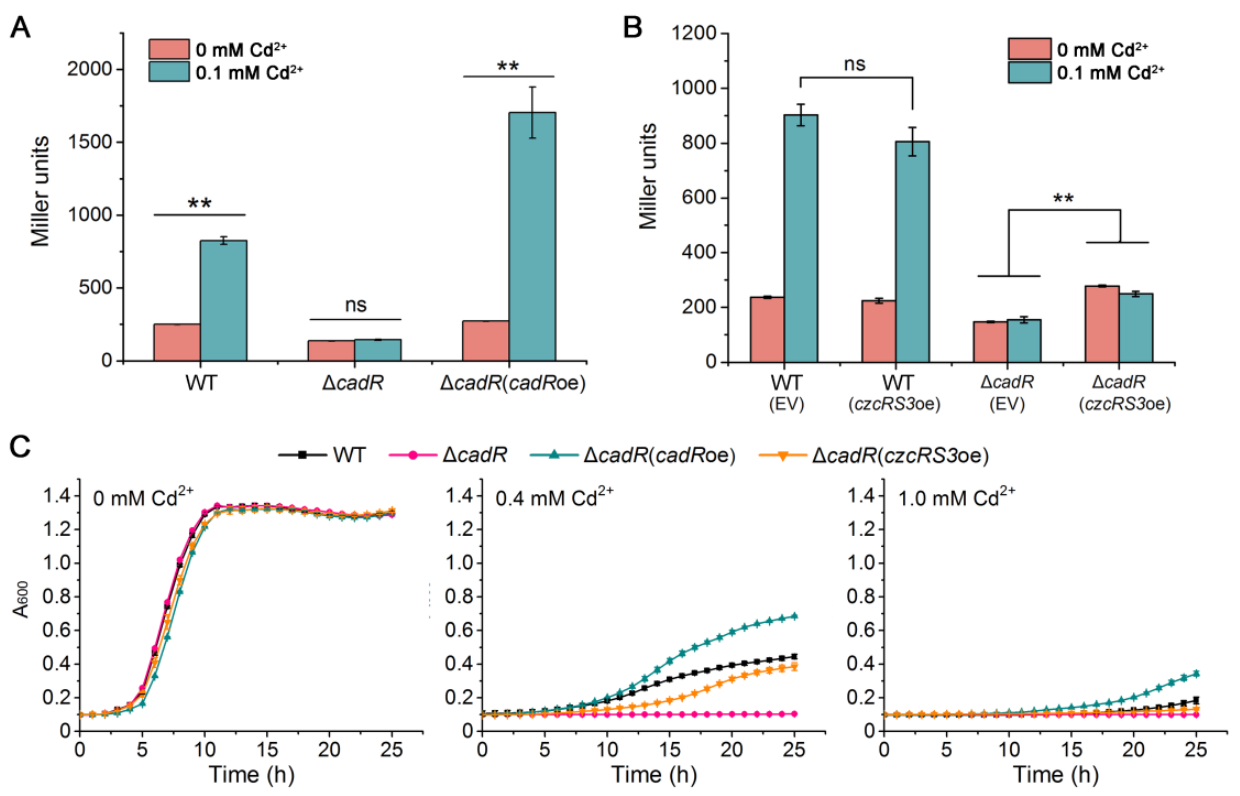

Figure 5. Involvement of CadR in $c z c R S 3$ expression. (A) The expression level of $c z c R S 3$ in wildtype KT2440 (WT), deletion $\Delta c a d R$, and overexpressed $\Delta c a d R$ (cadRoe) which harbors pB403-cadR. (B) The expression level of $c z c R S 3$ in KT2440 strains with overexpressed $c z c R S 3$. The activity of $\beta$ galactosidase expressed from $\mathrm{pBRTZ}-c z c R 3$ was measured after treatment with or without $\mathrm{CdCl}_{2}$ for $4 \mathrm{~h}$. (C) The growth of $\Delta c a d R$ with overexpressed $c a d R$ (cadRoe) or $c z c R S 3$ (czcRS3oe) in LB medium supplemented with $\mathrm{CdCl}_{2}$ at the indicated concentrations. The data represent the mean \pm standard deviation of three replicates. The significant difference was determined by Student's $t$-test $\left({ }^{* *} p<0.01\right.$; ns, non-significant, $p>0.05$ ). 
To test whether the binding of CzcR3 on its own promoter had physiological significance in the context of knocking out $c a d R$, the plasmid carrying the inducible $c z c R S 3$ was introduced into $\Delta c a d R$, as well as the wild-type. Overexpression of $c z c R S 3$ slightly activated the $c z c R 3$ promoter in $\Delta c a d R$, and this activation was not dependent on supplementation with $\mathrm{Cd}^{2+}$ (Figure 5B). In comparison, it could not cause a significant change in the expression level of $c z c R S 3$ in the wild-type (Figure 5B). The weak activation effect of the overexpressed CzcRS3 in czcRS3 expression is possibly masked by CadR in the wild-type. The effect of overexpressed CzcRS3 on cadmium resistance was also tested under the background of $\Delta c a d R$. The cadmium resistance was significantly reduced after $c a d R$ was knocked out (Figure 5 C), because $c a d R$ knockout would block the activation of $c a d A$, which encodes a major cadmium efflux pump [34,52]. Complementation with cadR increased the cadmium resistance of $\Delta c a d R$ to the wild-type level, while overexpression of $c z c R S 3$ could also restore the cadmium resistance of $\Delta c a d R$ to a certain extent (Figure 5C). This indicates that the regulatory effect of $\mathrm{CadR}$ on cadmium resistance partly depends on CzcRS3. In other words, CzcRS3 is a downstream regulator of CadR, and together they endow P. putida KT2440 with strong resistance to cadmium.

\subsection{CadR Binds to czcRS3 Promoter Directly}

To investigate whether CadR regulated czcRS3 expression directly, the His-tagged CadR was purified and its affinity for $c z c R S 3$ promoter was tested. The EMSA result showed that the purified CadR was able to bind to the DNA fragment containing the $c z c R S 3$ promoter (Figure 6A). This binding process did not require the participation of $\mathrm{Cd}^{2+}$, in agreement with previous work [30]. Furthermore, the DNase I footprinting assay identified the region protected by CadR from DNase I, which was located at -35 to $-59 \mathrm{bp}$, relative to the first codon of $c z c R 3$ (Figure 6C). An obvious inverted repeat sequence (CTTGACCCTG-N9-CAGGGTCAAG) was found over this region. The sequence of CadRbinding region on $c z c R S 3$ promoter is highly similar to that on the $c a d A$ promoter [30], further supporting this result. To verify the CadR-binding region on $c z c R S 3$ promoter, several base mutations were introduced in the promoter fragment (TTGACAAAG-N9CAAAGTC) for EMSA. As expected, the point-mutated fragment could not interact with CadR (Figure 6B). These results indicate that CadR regulates $c z c R S 3$ by directly binding its promoter.

Since CadR functions in a homodimer form, its binding site on DNA shows the characteristic of an inverted repeat. The binding of CadR to the promoter does not require metal ions; however, the CadR structure would change after binding to $\mathrm{Cd}^{2+}$, resulting in a distortion of the DNA and a reduced distance between the -10 and -35 elements of the promoter. This further leads the promoter to change from a repressed state to an activated state [30]. Although CadR can interact with $\mathrm{Cd}^{2+}, \mathrm{Pb}^{2+}$, and $\mathrm{Zn}^{2+}$, its binding affinity for $\mathrm{Pb}^{2+}$ and $\mathrm{Zn}^{2+}$ is much weaker than for $\mathrm{Cd}^{2+}[30]$. Therefore, $\mathrm{Cd}^{2+}$ can strongly induce expression of the CadR-regulated genes, whereas $\mathrm{Pb}^{2+}$ and $\mathrm{Zn}^{2+}$ have weaker effects [52]. This also explains the differences in degrees of induction in $c z c R S 3$ expression by $\mathrm{Cd}^{2+}$, $\mathrm{Pb}^{2+}$, and $\mathrm{Zn}^{2+}$ (Figure $4 \mathrm{~A}$ ). 
A
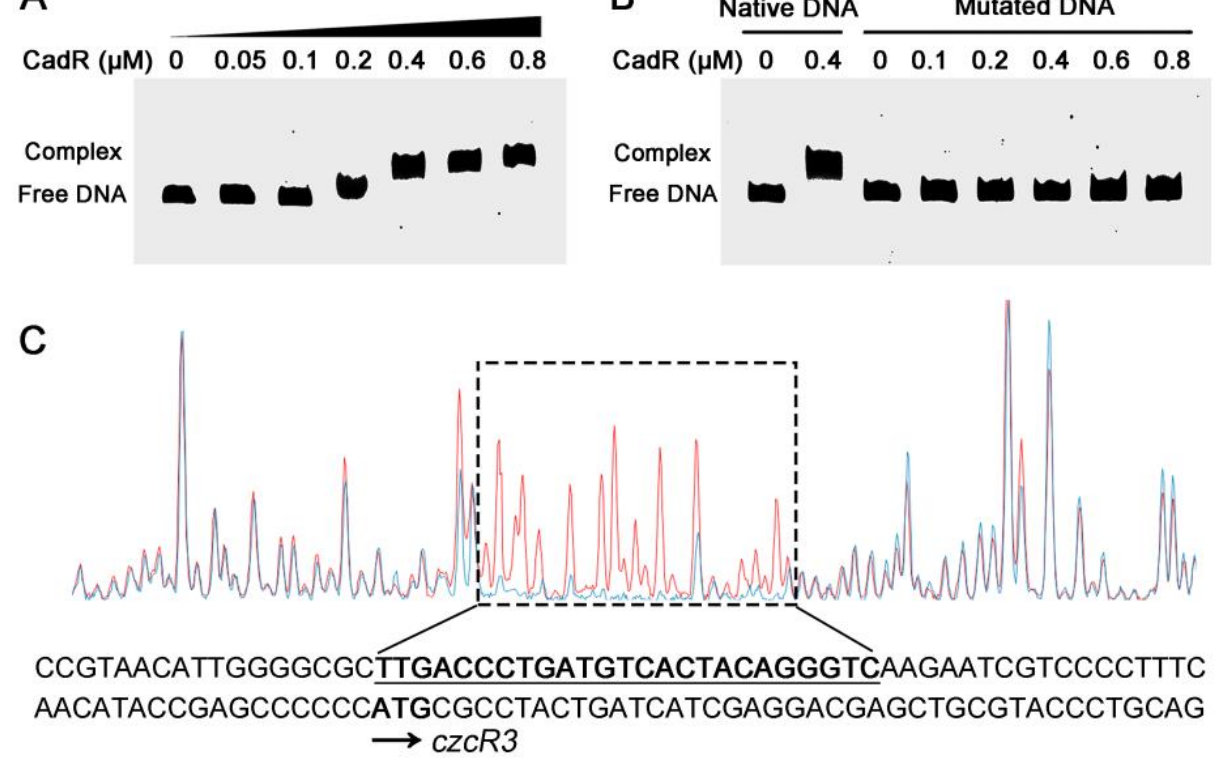

Figure 6. CadR directly binds to the $c z c R S 3$ promoter. The native (A) and mutated (B) probes of $c z c R S 3$ promoter were subjected to EMSA with the purified CadR. (C) The binding site of CadR on $c z c R S 3$ promoter was identified by DNase I footprinting assay, in which the native probe was incubated with CadR (blue peak) or BSA (red peak, as control). The region in the dashed box represents the binding region of CadR on $c z c R S 3$ promoter.

\section{Materials and Methods}

\subsection{Bacterial Strains and Growth Conditions}

All bacterial strains and plasmids used in this study are listed in Table S1. Throughout the study, the P. putida strains were grown in Lysogeny broth (LB) medium at $28^{\circ} \mathrm{C}$, and the E. coli strains were grown in LB medium at $37^{\circ} \mathrm{C}$. When required, antibiotics (purchased from Sangon Biotech, Shanghai, China) were used at the following concentrations: chloramphenicol ( $25 \mathrm{mg} / \mathrm{L})$, gentamycin $(20 \mathrm{mg} / \mathrm{L})$, tetracycline $(20 \mathrm{mg} / \mathrm{L})$, kanamycin $(50 \mathrm{mg} / \mathrm{L})$ and ampicillin $(150 \mathrm{mg} / \mathrm{L})$. Analytical-grade salts of $\mathrm{CdCl}_{2} \cdot 2.5 \mathrm{H}_{2} \mathrm{O}, \mathrm{CoCl}_{2} \cdot 6 \mathrm{H}_{2} \mathrm{O}$, $\mathrm{CrCl}_{3} \cdot 6 \mathrm{H}_{2} \mathrm{O}, \mathrm{CuCl}_{2} \cdot 2 \mathrm{H}_{2} \mathrm{O}, \mathrm{MnCl}_{2} \cdot 4 \mathrm{H}_{2} \mathrm{O}, \mathrm{NiCl}_{2} \cdot 6 \mathrm{H}_{2} \mathrm{O}, \mathrm{Pb}\left(\mathrm{NO}_{3}\right)_{2}$, and $\mathrm{ZnCl}_{2}$ (purchased from Macklin, Shanghai, China) were used to prepare $1 \mathrm{M}$ stock solutions, which were sterilized by filtration.

\subsection{Construction of Strains and Plasmids}

Primers for mutant construction are listed in Table S2. To construct the knockout plasmids, the upstream and downstream regions of $c z c R S 3$ and $c a d R$, which were amplified from KT2440 genome by polymerase chain reaction (PCR), were fused into Sacl-digested pDS3.0 [53] using the ClonExpress II one step cloning kit (Vazyme, Nanjing, China), yielding pDS-czcRS3 and pDS-cadR, respectively. The plasmid in E. coli S17-1 was transferred to wild-type P. putida KT2440 for allelic exchange, and $s a c B$ counter-selection was used to select the mutants as described in detail previously [53,54]. Finally, $\Delta c z c R S 3$ and $\Delta c a d R$ were obtained.

To construct the reporter plasmids, the 300-600 bp DNA fragments containing the promoter region of the tested genes were amplified using the primers for promoter in Table S2, and the fragments were ligated to XbaI- and PstI-digested pBRTZ, which contains the promoter-less $\beta$-galactosidase encoding gene lac $Z$ [55], yielding the reporter plasmids for $c z c D, c a d A 1, c z c C 1, c a d A 2, c z c R 3, c z c C 2, c a d A 3$, and $c z c C$ (Table S1), respectively. To construct the overexpression plasmids, the DNA fragments containing $c z c R S 3$ or $c a d R$ encoding sequence were amplified using the primers for gene cloning in Table S2, and the fragments were ligated to EcoRI- and BamHI-digested pBBR1-403 [56] to yield pB403- 
$c z c R S 3$ and pB403-cadR, respectively. When needed, isopropyl $\beta$-D-1-thiogalactopyranoside (IPTG) was used as the inducer of tac promoter at a concentration of $0.1 \mathrm{mM}$. The plasmids above were hosted in E. coli S17-1, and they were transferred to derivative strains of P. putida KT2440 by biparental mating. To construct the plasmids for protein purification, the encoding sequence of $c z c R 3$ and $c a d R$ were amplified using the primers for protein purification in Table S2, and the fragments were ligated to NcoI- and XhoI-digested pET28a to yield pET28a-czcR3 and pET28a-cadR, respectively. These plasmids were hosted in E. coli BL21(DE3).

\subsection{Test for Susceptibility to Heavy Metals}

The overnight cultures of P. putida strains were diluted with fresh LB medium to an $\mathrm{OD}_{600}$ of 0.005 , and the metal salts were also serially diluted by 2 -fold in LB medium. The diluted culture $(75 \mu \mathrm{L})$ was mixed with an equal volume of diluted metal salts or antibiotics in a 96-well plate. The mixture was incubated at $28^{\circ} \mathrm{C}$ for $24 \mathrm{~h}$. The minimum inhibitory concentration (MIC) was defined as the lowest concentration of antibiotic with no visible bacterial growth [57]. In the growth assays, the diluted cultures containing $\mathrm{Cd}^{2+}$ were incubated in Spark 20M microplate reader (Tecan, Männedorf, Switzerland) and the absorbance at $600 \mathrm{~nm}\left(\mathrm{~A}_{600}\right)$ was measured at intervals of $1 \mathrm{~h}$.

\subsection{Measurement of $\beta$-Galactosidase Activity}

An overnight culture of KT2440 strains harboring the reporter plasmid was inoculated in fresh LB medium (1:100). To reduce the effect of the hazardous heavy metals on growth, the cultures were pre-incubated for $8 \mathrm{~h}$, and then treated with heavy metal ions for $4 \mathrm{~h}$. The $\beta$-galactosidase activity was measured according to the procedures described previously $[54,58]$. Briefly, the reaction system contained $50 \mu \mathrm{L}$ culture samples, $450 \mu \mathrm{L}$ $Z$ buffer $\left(60 \mathrm{mM} \mathrm{Na}_{2} \mathrm{HPO}_{4}, 40 \mathrm{mM} \mathrm{NaH} \mathrm{PO}_{4}, 10 \mathrm{mM} \mathrm{KCl}, 1 \mathrm{mM} \mathrm{MgSO}_{4}\right.$ and $50 \mathrm{mM}$ $\beta$-mercaptoethanol), $25 \mu \mathrm{L}$ of $1 \mathrm{mg} / \mathrm{mL}$ sodium dodecyl sulfate (SDS), $50 \mu \mathrm{L}$ chloroform, and $100 \mu \mathrm{L}$ of $4 \mathrm{mg} / \mathrm{mL} 2$-nitrophenyl- $\beta$-D-galactopyranoside (ONPG). The reaction proceeded at $28{ }^{\circ} \mathrm{C}$ and was terminated by $250 \mu \mathrm{L}$ of $1 \mathrm{M} \mathrm{Na}_{2} \mathrm{CO}_{3}$. After centrifugation, Absorbance at $420 \mathrm{~nm}\left(\mathrm{~A}_{420}\right)$ of the supernatant was measured, and $\mathrm{A}_{600}$ of the bacterial culture before lysis was also measured. The $\beta$-galactosidase activity was calculated as: Miller units $=1000 \times\left(\mathrm{A}_{420} / \mathrm{A}_{600} /\right.$ volume $/$ time $)$.

\subsection{Identification of Transcription Start Site}

Total RNA was isolated from wild-type KT2440 culture after treatment with $0.2 \mathrm{mM}$ $\mathrm{Cd}^{2+}$ for $4 \mathrm{~h}$. The 5'-rapid amplification of cDNA ends (5'-RACE) was performed using the vaccinia capping enzyme (VCE, NewEnglandBiolabs, Ipswich, MA, USA) to add a $5^{\prime}$ end cap structure to the RNA sample [59]. The RNA sample was then treated by DNase I (Takara, Japan) to remove the residual genome DNA and purified by standard ethanol precipitation as described in the manual for DNase I. First-strand cDNA was synthesized using HiScript II reverse transcriptase (Vazyme, China) and primer czcRS3-RC (Table S2). Then, the template-switching oligonucleotide TSO-RNA (Table S2) was used as the template for reverse transcriptase to add the adapter sequence to the $3^{\prime}$ end of cDNA. The final cDNA was amplified using primers $c z c R S 3-\mathrm{RC}$ and TSO-DNA (Table S2), and the product was linked to pMD19-T (Takara, Japan). The transcription start site of $c z c R S 3$ operon was identified through sequencing.

\subsection{Purification of His-Tagged $C z c R 3$ and $C a d R$}

The E. coli BL21(DE3) strains harboring pET28a-czcR3 or pET28a-cadR were incubated in $500 \mathrm{~mL}$ LB medium with shaking at $220 \mathrm{rpm}$ to an $\mathrm{OD}_{600}$ of 0.5 . The cultures were treated with $0.5 \mathrm{mM}$ IPTG at $20^{\circ} \mathrm{C}$ for $6 \mathrm{~h}$. The cells were collected by centrifugation and resuspended in $20 \mathrm{~mL}$ of lysis buffer $(10 \mathrm{mM}$ Tris- $\mathrm{HCl}$ at $\mathrm{pH} 8.0,50 \mathrm{mM} \mathrm{NaCl}, 10 \% v / v$ glycerol). After the cells were lysed by a high-pressure homogenizer, the His-tagged CzcR3 and CadR were purified using Ni-NTA spin columns (BBI Life Sciences, China), according 
to the directions from the manufacturer. The His-tagged proteins were eluted with E250 buffer (10 mM Tris- $\mathrm{HCl}$ at $\mathrm{pH}$ 8.0, $250 \mathrm{mM} \mathrm{NaCl}, 10 \% v / v$ glycerol, $250 \mathrm{mM}$ imidazole). The elution samples were dialyzed to remove imidazole.

\subsection{Generation of Fluorescent Probes of Promoters}

The primers for the generation of the FAM-tagged probes are listed in Table S2. Primers M13F-czcR3pS and $c z c R 3 \mathrm{pA} 2$ were used to amplify the fragment containing the $c z c R 3$ promoter in the first round of $\mathrm{PCR}$, and then primers M13F-fam and $c z c R 3 \mathrm{pA} 2$ were used to add the fluorescent 6-carboxyfluorescein phosphoramidite (6-FAM) tag to the fragment in the second round of PCR. After the purification, the native probe for EMSA and DNase I footprinting assays was obtained. The FAM-tagged probes for $c z c C 1$ and $c z c C 2$ were generated following the same steps but using their specific primers. To generate the mutated probe of $c z c R 3$ promoter, two fragments, which were amplified from genome DNA by M13F-czcR3pS/czcR3p-mA and $c z c R 3 p A 2 / c z c R 3 p-m S$, respectively, were spliced by overlap extension PCR using M13F-fam and $c z c R 3 p A 2$.

\subsection{Electrophoretic Mobility Shift Assay (EMSA)}

In EMSA, $10 \mathrm{nM}$ of FAM-tagged probe was mixed with increasing concentrations of the purified protein (CzcR3 and CadR) in a $20 \mu \mathrm{L}$ binding buffer system (10 mM Tris$\mathrm{HCl}$ at $\mathrm{pH} 8.0,50 \mathrm{mM} \mathrm{KCl}, 5 \mathrm{mM} \mathrm{MgCl} 2,5 \% v / v$ glycerol). In the binding system for CzcR3, the carbamyl phosphate was used as the donor of phosphate group. After $20 \mathrm{~min}$ of incubation at $28^{\circ} \mathrm{C}, 15 \mu \mathrm{L}$ of the sample was loaded onto a $5 \%(w / v)$ polyacrylamide gel and electrophoresed in TG buffer (12.5 mM Tris- $\mathrm{HCl}$ at $\mathrm{pH} 8.3,96 \mathrm{mM}$ glycine) at $100 \mathrm{~V}$ on ice for $90 \mathrm{~min}$. The gels were photographed with ChemiDocXRS + (BioRad, Hercules, CA, USA).

\subsection{DNase I Footprinting Assay}

In DNase I footprinting assay, $40 \mathrm{nM}$ of the FAM-tagged probe was mixed with about $2 \mu \mathrm{M}$ of the purified protein or bovine serum albumin (BSA, negative control) in a $200 \mu \mathrm{L}$ binding buffer system. After $20 \mathrm{~min}$ of incubation at $28^{\circ} \mathrm{C}$, the samples were treated with $0.3 \mathrm{U}$ DNase I at room temperature for $5 \mathrm{~min}$, and the reaction was quenched by treatment with $100 \mu \mathrm{L}$ phenol-chloroform $(1: 1, v / v)$ and $80^{\circ} \mathrm{C}$ heating. After centrifugation, the supernatant was mixed with $500 \mu \mathrm{L}$ ethanol and $20 \mu \mathrm{L}$ of $3 \mathrm{M}$ sodium acetate (pH 5.2). The

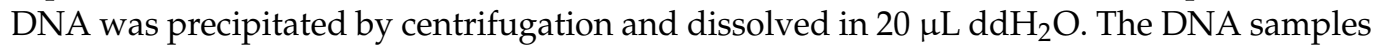
were analyzed by 3730XL DNA Sequencer and the data was processed by Peak Scanner Software v1.0 (Applied Biosystems, Waltham, MA, USA).

\section{Conclusions}

In this study, the role of a two-component system CzcRS3 in cadmium resistance of P. putida KT2440 was investigated and confirmed that CzcRS3 regulated the expression of two CzcCBA efflux pump operons by directly binding to their promoters. The regulation of $c z c R S 3$ expression was also explored and determined that CzcR3 bound to its own promoter in an atypical way, but this did not have a significant effect on transcription. Importantly, the expression of $c z c R S 3$ was directly regulated by CadR in response to $\mathrm{Cd}^{2+}$, $\mathrm{Zn}^{2+}$, and $\mathrm{Pb}^{2+}$, revealing the regulatory relationship between the Cad and Czc systems. Along with previous studies, these results support that these two systems essentially belong to a biological pathway (Figure 7). In this pathway, $\mathrm{Cd}^{2+}$ enters the cell and combines with CadR, and thereby CadR can promote the expression of the CadA3 efflux pump [30] and CzcRS3. CadA3 functions in the transport of $\mathrm{Cd}^{2+}$ from the cytoplasm to the periplasm [34], and CzcRS3 is responsible for activating the expression of two CzcCBA efflux pumps. CzcCBA can expel, not only part of the intracellular $\mathrm{Cd}^{2+}$, but also the $\mathrm{Cd}^{2+}$ in the periplasm that includes the $\mathrm{Cd}^{2+}$ exported from the cytoplasm by CadA, to the outside [33]. These two efflux systems, including their regulators, form effective cooperation to protect the P. putida from toxic cadmium in the environment. 


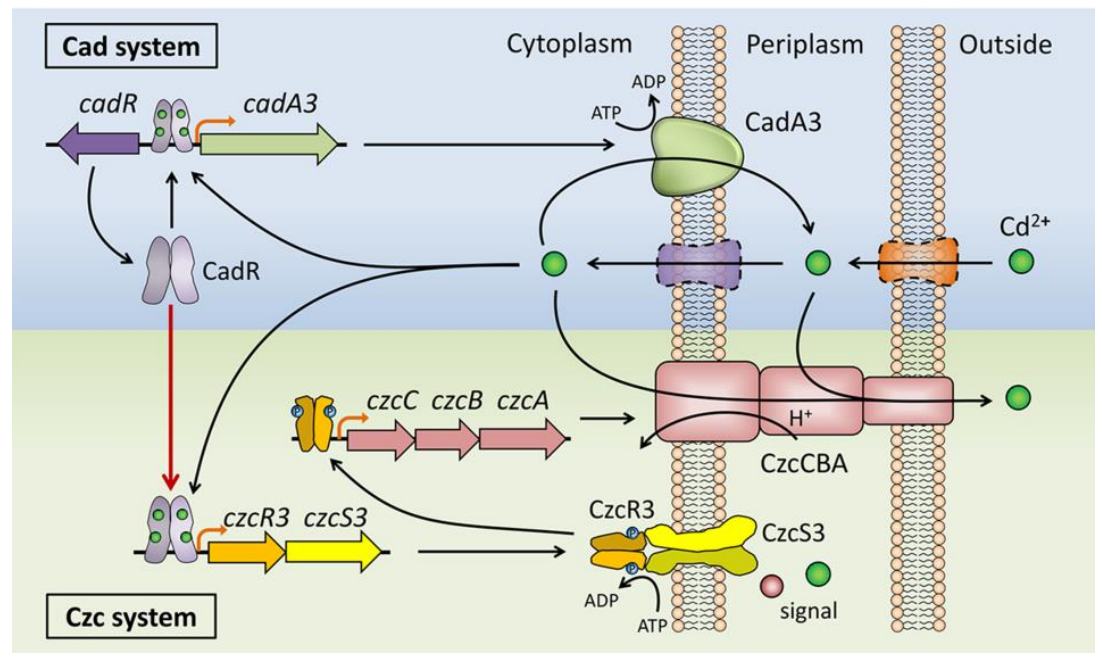

Figure 7. Cooperation between Czc and Cad systems confers P. putida the resistance to cadmium.

Supplementary Materials: The following are available online at https:/ / www.mdpi.com/article/10 $.3390 /$ ijms22189697/s1.

Author Contributions: Conceptualization, H.L.; funding acquisition, H.L.; investigation, H.L.; methodology, Y.Z. and Y.W.; project administration, X.X. and Q.S.; software, Y.W.; validation, H.L. and Y.Z.; writing—original draft, H.L.; writing—review and editing, H.L., X.X. and Q.S. All authors have read and agreed to the published version of the manuscript.

Funding: This research was funded by the National Natural Science Foundation of China (31900086), GDAS' Project of Science and Technology Development (2019GDASYL-0103010), and Guangdong Science and Technology Program (2017B030314045).

Institutional Review Board Statement: Not applicable.

Informed Consent Statement: Not applicable.

Data Availability Statement: The data presented in this study are available on request from the corresponding author.

Acknowledgments: The authors thank the Guangdong Detection Center of Microbiology for support on the research platform.

Conflicts of Interest: The authors declare no conflict of interest.

\section{References}

1. Liu, F.; Chen, X.; Liu, Y.; Niu, Z.; Tang, H.; Mao, S.; Li, N.; Chen, G.; Xiang, H. Serum cardiovascular-related metabolites disturbance exposed to different heavy metal exposure scenarios. J. Hazard. Mater. 2021, 415, 125590. [CrossRef]

2. Gao, Y.; Wang, R.; Li, Y.; Ding, X.; Jiang, Y.; Feng, J.; Zhu, L. Trophic transfer of heavy metals in the marine food web based on tissue residuals. Sci. Total. Environ. 2021, 772, 145064. [CrossRef]

3. Sun, Z.; Xie, X.; Wang, P.; Hu, Y.; Cheng, H. Heavy metal pollution caused by small-scale metal ore mining activities: A case study from a polymetallic mine in South China. Sci. Total. Environ. 2018, 639, 217-227. [CrossRef]

4. Huttunen-Saarivirta, E.; Korpiniemi, H.; Kuokkala, V.T.; Paajanen, H. Corrosion of cadmium plating by runway de-icing chemicals: Study of surface phenomena and comparison of corrosion tests. Surf. Coat. Tech. 2013, 232, 101-115. [CrossRef]

5. Xiao, J.; Huang, J.; Wang, M.; Huang, M.; Wang, Y. The fate and long-term toxic effects of NiO nanoparticles at environmental concentration in constructed wetland: Enzyme activity, microbial property, metabolic pathway and functional genes. J. Hazard. Mater. 2021, 413, 125295. [CrossRef] [PubMed]

6. Jiang, B.; Adebayo, A.; Jia, J.L.; Xing, Y.; Deng, S.Q.; Guo, L.M.; Liang, Y.T.; Zhang, D.Y. Impacts of heavy metals and soil properties at a Nigerian e-waste site on soil microbial community. J. Hazard. Mater. 2019, 362, 187-195. [CrossRef] [PubMed]

7. Nies, D.H. Microbial heavy-metal resistance. Appl. Microbiol. Biot. 1999, 51, 730-750. [CrossRef]

8. Smith, R.L.; Maguire, M.E. Distribution of the cora $\mathrm{Mg}(2+)$ transport-system in Gram-negative bacteria. J. Bacteriol. 1995, 177, 1638-1640. [CrossRef] [PubMed] 
9. Grass, G.; Wong, M.D.; Rosen, B.P.; Smith, R.L.; Rensing, C. ZupT is a Zn(II) uptake system in Escherichia coli. J. Bacteriol. 2002, 184, 864-866. [CrossRef]

10. Que, Q.; Helmann, J.D. Manganese homeostasis in Bacillus subtilis is regulated by MntR, a bifunctional regulator related to the diphtheria toxin repressor family of proteins. Mol. Microbiol. 2000, 35, 1454-1468. [CrossRef]

11. Ammendola, S.; Cerasi, M.; Battistoni, A. Deregulation of transition metals homeostasis is a key feature of cadmium toxicity in Salmonella. Biometals 2014, 27, 703-714. [CrossRef] [PubMed]

12. Wu, X.; Cobbina, S.J.; Mao, G.; Xu, H.; Zhang, Z.; Yang, L. A review of toxicity and mechanisms of individual and mixtures of heavy metals in the environment. Environ. Sci. Pollut. Res. Int. 2016, 23, 8244-8259. [CrossRef] [PubMed]

13. Kim, J.J.; Kim, Y.S.; Kumar, V. Heavy metal toxicity: An update of chelating therapeutic strategies. J. Trace Elem. Med. Biol. 2019, 54, 226-231. [CrossRef] [PubMed]

14. Wu, Q.M.; Hu, W.Y.; Wang, H.F.; Liu, P.; Wang, X.K.; Huang, B.A. Spatial distribution, ecological risk and sources of heavy metals in soils from a typical economic development area, Southeastern China. Sci. Total. Environ. 2021, 780, 146557. [CrossRef] [PubMed]

15. Chen, Z.K.; Huang, B.; Hu, W.Y.; Wang, W.X.; Muhammad, I.; Lu, Q.Q.; Jing, G.H.; Zhang, Z. Ecological-health risks assessment and source identification of heavy metals in typical greenhouse vegetable production systems in Northwest China. Environ. Sci. Pollut. Res. 2021, 28, 42583-42595. [CrossRef]

16. Comte, S.; Guibaud, G.; Baudu, M. Biosorption properties of extracellular polymeric substances (EPS) towards $\mathrm{Cd}, \mathrm{Cu}$ and $\mathrm{Pb}$ for different $\mathrm{pH}$ values. J. Hazard. Mater. 2008, 151, 185-193. [CrossRef]

17. Blindauer, C.A. Bacterial metallothioneins: Past, present, and questions for the future. J. Biol. Inorg. Chem. 2011, 16, 1011-1024. [CrossRef]

18. Gallardo-Benavente, C.; Carrion, O.; Todd, J.D.; Pieretti, J.C.; Seabra, A.B.; Duran, N.; Rubilar, O.; Perez-Donoso, J.M.; Quiroz, A. Biosynthesis of CdS quantum dots mediated by volatile sulfur compounds released by antarctic Pseudomonas fragi. Front. Microbiol. 2019, 10, 1866. [CrossRef]

19. Shi, Z.J.; Zhang, Z.F.; Yuan, M.; Wang, S.; Yang, M.; Yao, Q.; Ba, W.N.; Zhao, J.; Xie, B. Characterization of a high cadmium accumulating soil bacterium, Cupriavidus sp. WS2. Chemosphere 2020, 247, 125834. [CrossRef]

20. Nies, D.H. Efflux-mediated heavy metal resistance in prokaryotes. FEMS Microbiol. Rev. 2003, 27, 313-339. [CrossRef]

21. Nanda, M.; Kumar, V.; Sharma, D.K. Multimetal tolerance mechanisms in bacteria: The resistance strategies acquired by bacteria that can be exploited to 'clean-up' heavy metal contaminants from water. Aquat. Toxicol. 2019, 212, 1-10. [CrossRef] [PubMed]

22. Cai, X.C.; Zheng, X.; Zhang, D.N.; Iqbal, W.; Liu, C.K.; Yang, B.; Zhao, X.; Lu, X.Y.; Mao, Y.P. Microbial characterization of heavy metal resistant bacterial strains isolated from an electroplating wastewater treatment plant. Ecotox. Environ. Safe 2019, 181, 472-480. [CrossRef]

23. Xia, X.; Wu, S.J.; Zhou, Z.J.; Wang, G.J. Microbial Cd(II) and Cr(VI) resistance mechanisms and application in bioremediation. J. Hazard. Mater. 2021, 401, 123685. [CrossRef] [PubMed]

24. Rensing, C.; Pribyl, T.; Nies, D.H. New functions for the three subunits of the CzcCBA cation-proton antiporter. J. Bacteriol. 1997, 179, 6871-6879. [CrossRef] [PubMed]

25. Nies, D.H. The cobalt, zinc, and cadmium efflux system CzcABC from Alcaligenes eutrophus functions as a cation-proton antiporter in Escherichia coli. J. Bacteriol. 1995, 177, 2707-2712. [CrossRef]

26. Dieppois, G.; Ducret, V.; Caille, O.; Perron, K. The transcriptional regulator CzcR modulates antibiotic resistance and quorum sensing in Pseudomonas aeruginosa. PLoS ONE 2012, 7, e38148. [CrossRef]

27. Wang, D.; Chen, W.; Huang, S.; He, Y.; Liu, X.; Hu, Q.; Wei, T.; Sang, H.; Gan, J.; Chen, H. Structural basis of Zn(II) induced metal detoxification and antibiotic resistance by histidine kinase CzcS in Pseudomonas aeruginosa. PLoS Pathog. 2017, 13, e1006533. [CrossRef]

28. Anton, A.; Grosse, C.; Reissmann, J.; Pribyl, T.; Nies, D.H. CzcD is a heavy metal ion transporter involved in regulation of heavy metal resistance in Ralstonia sp. strain CH34. J. Bacteriol. 1999, 181, 6876-6881. [CrossRef] [PubMed]

29. Barnawi, H.; Masri, N.; Hussain, N.; Al-Lawati, B.; Mayasari, E.; Gulbicka, A.; Jervis, A.J.; Huang, M.H.; Cavet, J.S.; Linton, D. RNA-based thermoregulation of a Campylobacter jejuni zinc resistance determinant. PLoS Pathog. 2020, 16, e1009008. [CrossRef] [PubMed]

30. Liu, X.; Hu, Q.; Yang, J.; Huang, S.; Wei, T.; Chen, W.; He, Y.; Wang, D.; Liu, Z.; Wang, K.; et al. Selective cadmium regulation mediated by a cooperative binding mechanism in CadR. Proc. Natl. Acad. Sci. USA 2019, 116, 20398-20403. [CrossRef] [PubMed]

31. Wu, C.C.; Gardarin, A.; Martel, A.; Mintz, E.; Guillain, F.; Catty, P. The cadmium transport sites of CadA, the Cd ${ }^{2+}-$ ATPase from Listeria monocytogenes. J. Biol. Chem. 2006, 281, 29533-29541. [CrossRef]

32. Endo, G.; Silver, S. CadC, the transcriptional regulatory protein of the cadmium resistance system of Staphylococcus aureus plasmid pI258. J. Bacteriol. 1995, 177, 4437-4441. [CrossRef] [PubMed]

33. Legatzki, A.; Grass, G.; Anton, A.; Rensing, C.; Nies, D.H. Interplay of the Czc system and two P-type ATPases in conferring metal resistance to Ralstonia metallidurans. J. Bacteriol. 2003, 185, 4354-4361. [CrossRef]

34. Leedjarv, A.; Ivask, A.; Virta, M. Interplay of different transporters in the mediation of divalent heavy metal resistance in Pseudomonas putida KT2440. J. Bacteriol. 2008, 190, 2680-2689. [CrossRef] [PubMed] 
35. Martin-Pascual, M.; Batianis, C.; Bruinsma, L.; Asin-Garcia, E.; Garcia-Morales, L.; Weusthuis, R.A.; van Kranenburg, R.; Martins Dos Santos, V.A.P. A navigation guide of synthetic biology tools for Pseudomonas putida. Biotechnol. Adv. $2021,49,107732$. [CrossRef]

36. Zhao, Y.X.; Che, Y.; Zhang, F.; Wang, J.C.; Gao, W.X.; Zhang, T.; Yang, C. Development of an efficient pathway construction strategy for rapid evolution of the biodegradation capacity of Pseudomonas putida KT2440 and its application in bioremediation. Sci. Total. Environ. 2021, 761, 143239. [CrossRef]

37. Fernandez-Lopez, C.; Posada-Baquero, R.; Garcia, J.L.; Castilla-Alcantara, J.C.; Cantos, M.; Ortega-Calvo, J.J. Root-mediated bacterial accessibility and cometabolism of pyrene in soil. Sci. Total. Environ. 2021, 760, 143408. [CrossRef] [PubMed]

38. Kohlstedt, M.; Starck, S.; Barton, N.; Stolzenberger, J.; Selzer, M.; Mehlmann, K.; Schneider, R.; Pleissner, D.; Rinkel, J.; Dickschat, J.S.; et al. From lignin to nylon: Cascaded chemical and biochemical conversion using metabolically engineered Pseudomonas putida. Metab. Eng. 2018, 47, 279-293. [CrossRef]

39. Nikel, P.I.; de Lorenzo, V. Pseudomonas putida as a functional chassis for industrial biocatalysis: From native biochemistry to trans-metabolism. Metab. Eng. 2018, 50, 142-155. [CrossRef]

40. Hu, N.; Zhao, B. Key genes involved in heavy-metal resistance in Pseudomonas putida CD2. FEMS Microbiol. Lett. 2007, 267, 17-22. [CrossRef]

41. Liu, P.L.; Chen, X.; Huang, Q.Y.; Chen, W.L. The role of CzcRS two-component systems in the heavy metal resistance of Pseudomonas putida X4. Int. J. Mol. Sci. 2015, 16, 17005-17017. [CrossRef] [PubMed]

42. Bagdasarian, M.; Lurz, R.; Ruckert, B.; Franklin, F.C.H.; Bagdasarian, M.M.; Frey, J.; Timmis, K.N. Specific-purpose plasmid cloning vectors. II. Broad host range, high copy number, RSF1010-derived vectors, and a host-vector system for gene cloning in Pseudomonas. Gene 1981, 16, 237-247. [CrossRef]

43. Winsor, G.L.; Griffiths, E.J.; Lo, R.; Dhillon, B.K.; Shay, J.A.; Brinkman, F.S.L. Enhanced annotations and features for comparing thousands of Pseudomonas genomes in the Pseudomonas genome database. Nucleic Acids Res. 2016, 44, D646-D653. [CrossRef] [PubMed]

44. Canovas, D.; Cases, I.; de Lorenzo, V. Heavy metal tolerance and metal homeostasis in Pseudomonas putida as revealed by complete genome analysis. Environ. Microbiol. 2003, 5, 1242-1256. [CrossRef] [PubMed]

45. Agrawal, R.; Sahoo, B.K.; Saini, D.K. Cross-talk and specificity in two-component signal transduction pathways. Future Microbiol. 2016, 11, 685-697. [CrossRef]

46. Brocker, M.; Mack, C.; Bott, M. Target genes, consensus binding site, and role of phosphorylation for the response regulator MtrA of Corynebacterium glutamicum. J. Bacteriol. 2011, 193, 1237-1249. [CrossRef]

47. Jeon, Y.; Lee, Y.S.; Han, J.S.; Kim, J.B.; Hwang, D.S. Multimerization of phosphorylated and non-phosphorylated ArcA is necessary for the response regulator function of the Arc two-component signal transduction system. J. Biol. Chem. 2001, 276, 40873-40879. [CrossRef]

48. Brown, D.R.; Barton, G.; Pan, Z.S.; Buck, M.; Wigneshweraraj, S. Nitrogen stress response and stringent response are coupled in Escherichia coli. Nat. Commun. 2014, 5, 4115. [CrossRef]

49. Garber, M.E.; Rajeev, L.; Kazakov, A.E.; Trinh, J.; Masuno, D.; Thompson, M.G.; Kaplan, N.; Luk, J.; Novichkov, P.S.; Mukhopadhyay, A. Multiple signaling systems target a core set of transition metal homeostasis genes using similar binding motifs. Mol. Microbiol. 2018, 107, 704-717. [CrossRef]

50. Typas, A.; Becker, G.; Hengge, R. The molecular basis of selective promoter activation by the $\sigma^{S}$ subunit of RNA polymerase. Mol. Microbiol. 2007, 63, 1296-1306. [CrossRef]

51. Zhang, X.X.; Rainey, P.B. Dual involvement of CbrAB and NtrBC in the regulation of histidine utilization in Pseudomonas fluorescens SBW25. Genetics 2008, 178, 185-195. [CrossRef] [PubMed]

52. Lee, S.W.; Glickmann, E.; Cooksey, D.A. Chromosomal locus for cadmium resistance in Pseudomonas putida consisting of a cadmium-transporting ATPase and a MerR family response regulator. Appl. Environ. Microb. 2001, 67, 1437-1444. [CrossRef] [PubMed]

53. Gao, W.; Liu, Y.; Giometti, C.S.; Tollaksen, S.L.; Khare, T.; Wu, L.; Klingeman, D.M.; Fields, M.W.; Zhou, J. Knock-out of SO1377 gene, which encodes the member of a conserved hypothetical bacterial protein family COG2268, results in alteration of iron metabolism, increased spontaneous mutation and hydrogen peroxide sensitivity in Shewanella oneidensis MR-1. BMC Genom. 2006, 7, 76. [CrossRef]

54. Liu, H.; Yan, H.; Xiao, Y.; Nie, H.; Huang, Q.; Chen, W. The exopolysaccharide gene cluster pea is transcriptionally controlled by RpoS and repressed by AmrZ in Pseudomonas putida KT2440. Microbiol. Res. 2019, 218, 1-11. [CrossRef]

55. Liu, H.Z.; Xiao, Y.J.; Nie, H.L.; Huang, Q.Y.; Chen, W.L. Influence of (p)ppGpp on biofilm regulation in Pseudomonas putida KT2440. Microbiol. Res. 2017, 204, 1-8. [CrossRef] [PubMed]

56. Nie, H.L.; Xiao, Y.J.; Liu, H.Z.; He, J.Z.; Chen, W.L.; Huang, Q.Y. FleN and FleQ play a synergistic role in regulating lapA and $b c s$ operons in Pseudomonas putida KT2440. Env. Microbiol. Rep. 2017, 9, 571-580. [CrossRef] [PubMed]

57. Miyake, Y.; Fujiwara, S.; Usui, T.; Suginaka, H. Simple method for measuring the antibiotic concentration required to kill adherent bacteria. Chemotherapy 1992, 38, 286-290. [CrossRef] [PubMed]

58. Miller, J.H. Experiments in Molecular Genetics; Cold Spring Harbor Laboratory Press: Cold Spring Harbor, NY, USA, 1972.

59. Liu, F.; Zheng, K.; Chen, H.C.; Liu, Z.F. Capping-RACE: A simple, accurate, and sensitive 5' RACE method for use in prokaryotes. Nucleic Acids Res. 2018, 46, e129. [CrossRef] 